\title{
Contact allergy to methylisothiazolinone in a deodorant
}

\section{Cristina Amaro, Raquel Santos and Jorge Cardoso}

Department of Dermatology, Hospital de Curry Cabral, 1069-166 Lisbon, Portugal

doi:10.1111/j.1600-0536.2011.01885.x

Key words: allergic contact dermatitis; cosmetics; methylchloroisothiazolinone/methylisothiazolinone; methylisothiazolinone; preservatives.

Methylisothiazolinone (MI) (CAS 2682-20-4) is a preservative that was approved for use in cosmetics in 2005, with a maximum permitted concentration of $100 \mathrm{ppm}(0.01 \%)(1,2)$. Even though it was believed to be a safer alternative to the previous methylchloroisothiazolinone (MCI)/MI mixture, several cases of contact allergy to this compound have recently been reported $(3,4)$.

Correspondence: Cristina Amaro, Rua da Beneficência, no. 8, 1069-166 Lisbon, Portugal. Tel: +351966188318. E-mail: cristinacamaro@sapo.pt

Conflicts of interest: The authors have declared no conflicts.

\section{Case Report}

A 37-year-old atopic woman presented with a 1-week history of eczematous lesions affecting both axillae. She had been using a new deodorant, Mineral ${ }^{\circledR}$ (Garnier, L'Oréal, Portugal), for the previous 2 weeks. There was a past history of jewellery intolerance, and she did not report any previous skin reactions to perfumes and deodorants. She was treated with topical corticosteroids, and there was complete remission of the lesions in a few days.

Patch testing was performed with Finn Chambers ${ }^{\circledR}$ and according to the International Contact Dermatitis Research Group criteria, with the Portuguese baseline series, a fragrance series, and her own product. The patient reacted to nickel $(++), \mathrm{MCI} / \mathrm{MI} 100 \mathrm{ppm}(++)$, 
and to the deodorant $(++)$. A repeated open application test performed on the volar part of the forearm with the deodorant gave a strongly positive result at D2. The patient was patch tested again with MI 200 ppm (Chemotechnique) (++ at D2).

\section{Discussion}

Isothiazolinones are effective preservatives used in a wide variety of industrial lacquers, varnishes, inks, household products, and cosmetics $(3,4)$. The first occupational cases of isolated MI contact allergy were reported in 2004 (5) and 2006 (6), after handling of wallpaper glue and paint, respectively.

García-Gavín et al. published the first seven nonoccupational cases after the use of cosmetics that contained only MI (3). Six of them suffered from perineal eczema caused by wipes, and one from eyelid dermatitis resulting from make-up removal. Since then, other cases have been reported (7). In a retrospective investigation performed by Lundov et al., in which 2536 dermatitis patients were patch tested with MI (4), exposure caused by cosmetics, namely in hair care products, liquid soaps, creams, cleansing milk, and a suntan lotion, was found in $32 \%$ of the cases. As far as we know, this is the first case regarding a deodorant as a leave-on product.

Primary sensitization to MI seems to be the most reasonable explanation, although primary sensitization to MCI with cross-reactivity to MI cannot be excluded (3).

It should be noted that not only may patients who have been previously sensitized to the mixture $\mathrm{MCI} / \mathrm{MI}$ react to MI alone, but also that patients previously sensitized to MI may react to products containing $\mathrm{MCI} / \mathrm{MI}(3,8)$, and exposure to either of these molecules should be avoided in leave-on products.

\section{References}

1 The Cosmetics Directive of the European Union. Dir. 2005/42/EEC. Annex VI: List of Preservatives Which Cosmetic Products May Contain, 2005.

2 Burnett C L, Bergfeld W F, Belsito D V et al. Final report of the safety assessment of methylisothiazolinone. Int J Toxicol 2010: 29 (4 Suppl.): 187S-213S.

3 García-Gavín J, Vansina S, Kerre S, Naert A, Goossens A. Methylisothiazolinone, an emerging allergen in cosmetics? Contact Dermatitis 2010: 63: 96-101.
4 Lundov M D, Thyssen J P, Zachariae C, Johansen J D. Prevalence and cause of methylisothiazolinone contact allergy. Contact Dermatitis 2010: 63: 164-167.

5 Isaksson M, Gruvberger B, Bruze M. Occupational contact allergy and dermatitis from methylisothiazolinone after contact with wallcovering glue and after a chemical burn from a biocide. Dermatitis 2004: 15: 201-205.

6 Thyssen J P, Sederberg-Olsen N, Thomsen J F, Menné T. Contact dermatitis from methylisothiazolinone in a paint factory. Contact Dermatitis 2006: 54: 322-324.

7 García-Gavín J, Goossens A. Moist toilet paper: allergy to the nonhalogenated derivative methylisothiazolinone preservative alone. Arch Dermatol 2010: 146: 1186

8 Timmermans A, Hertog S, Gladys K, Vanacker H, Goossens A. 'Dermatologically tested' baby toilet tissues: a cause of allergic contact dermatitis in adults. Contact Dermatitis 2007: 57: 97-99. 
This document is a scanned copy of a printed document. No warranty is given about the accuracy of the copy. Users should refer to the original published version of the material. 